Psicologia Escolar

e Educacional
ARTIGO

DOI: http://dx.doi.org/10.1590/2175-35392021221843

Localizador - e221843

\title{
FORMAÇÃO DOCENTE: A ESCRITA DE SI NA APRENDIZAGEM DE PSICOLOGIA E SOCIOLOGIA
}

\author{
Elis Regina da Costa $^{1} \mathbb{D}$; Juliana Pereira Araújo ${ }^{1} \mathbb{D}$
}

\section{RESUMO}

No processo do fazer docente e fazer-se docente, a escrita de si nas disciplinas de Psicologia e Sociologia da Educação constitui um campo fecundo de intervenção, investigação e formação inicial de futuros professores. Alunos do curso de Pedagogia trouxeram à luz episódios que potencializaram um exercício de significar e ressignificar sua trajetória de vida, sua inserção nos grupos, sua subjetividade e singularidade, que foi dispositivo reflexivo valioso na aprendizagem significativa de conceitos da Psicologia e da Sociologia da Educação. Participaram alunos do Curso de Pedagogia de uma Universidade pública. A metodologia proposta consistiu em produções narrativas autobiográficas fundamentadas nas teorias estudadas no transcorrer das disciplinas de Psicologia e Sociologia da Educação. Concluiu-se que há na autobiografia, a presença pouco considerada de elementos que influem na formação alicerçando visões, aceites e recusas teóricas e necessita ser considerada na formação inicial.

Palavras-chave: formação de professores; narrativas; autobiografia.

\section{Teacher Education: the self-writing in the learning of Psychology and Sociology}

\begin{abstract}
In the process of teaching and becoming a teacher, self-writing in the disciplines of Psychology and Sociology of Education constitutes a fruitful field of intervention, research and initial training for future teachers. Students in the Pedagogy course brought to light episodes that potentiated an exercise in signifying and reframing their life trajectory, their insertion in groups, their subjectivity and uniqueness, which was a valuable reflective device in the meaningful learning of concepts from Psychology and Sociology of Education. Students from the Pedagogy Course at a public university participated. The proposed methodology consisted of autobiographical narrative productions based on the theories studied throughout the disciplines of Psychology and Sociology of Education. It was concluded that there is in the autobiography, the little-considered presence of elements that influence the formation supporting theoretical views, acceptances and refusals and needs to be considered in the initial formation.
\end{abstract}

Keywords: teacher training; narratives; autobiography.

\section{Formación Docente: la escritura de si en el aprendizaje de Psicología y Sociología}

\section{RESUMEN}

En proceso del hacer docente y hacerse docente, la escritura de si en las asignaturas de Psicología y Sociología de la educación constituyen un campo fecundo de intervención, investigación y formación inicial de futuros profesores. Alumnos del curso de Pedagogía trajeron a la luz episodios que potencializaron un ejercicio de significar y resignificar su trayectoria de vida, su inserción en los grupos, su subjetividad y singularidad, que fue dispositivo reflexivo valioso en el aprendizaje significativa de conceptos de la Psicología y de la Sociología de la Educación. Participaron alumnos del Curso de Pedagogía de una Universidad pública. La metodología propuesta consistió en producciones narrativas autobiográficas fundamentadas en las teorías estudiadas en el transcurrir de las asignaturas de Psicología y Sociología de la Educación. Se concluye que hay en la autobiografía, la presencia poco considerada de elementos que influyen en la formación basando visiones, aceptes y rechazos teóricos y necesita ser considerada en la formación inicial.

Palabras claves: formación de profesores; narrativas; autobiografía.

\footnotetext{
${ }^{1}$ Universidade Federal de Goiás - Catalão - GO - Brasil; eliscosta2012@ufg.br; juliana.barrado@gmail.com
} 


\section{INTRODUÇÃO}

A questão da formação de professores vem sendo largamente problematizada desde as últimas décadas do século XX tendo como base uma perspectiva que, na esteira dos estudos de Nóvoa (1992) aciona como premissa o fato de que o professor é uma pessoa. De modo geral, é reflexo do modo como a pesquisa em educação repercute um movimento maior de valorização do sujeito e da subjetividade que tem no Método Biográfico, surgido na Alemanha no final do século XIX como alternativa sociológica ao positivismo, representante fundamental e cuja sistemática se inicia com os sociólogos americanos da Escola de Chicago (Coulon, 1995) nos anos de 1920.

Na pesquisa sobre a temática da formação de professores emerge um interesse dos pesquisadores pela vida, carreira, percurso profissional, biografia e autobiografia pessoal dos professores que encontram na pesquisa autobiográfica um canal para colocar em evidência a voz do sujeito participante das investigações, o que consolida a oposição do método a uma visão dicotômica dos métodos convencionais de pesquisas entre investigador e investigado. Faz sentido pensar que os professores possuem de antemão, sobretudo pelas experiências como alunos, um conhecimento sobre o ensino estabelecido pelas imagens, pelos rituais, pelos costumes, rotinas e ritmos que têm por base a sua experiência.

$\mathrm{Na}$ formação inicial e continuada de professores o uso das autobiografias se fortalece a partir de sua vinculação às pesquisas na área educacional (Souza, Sousa, \& Catani, 2007) e encontra amparo em autores que valorizam o duplo processo de formar e de formar-se (Josso, 2010), a questão da experiência como âncora do movimento memória e formação (Larrosa, 2011; Ricoeur, 2007), e aqueles que avançam também da defesa do uso da autobiografia não apenas como uma metodologia, mas como uma perspectiva específica e autônoma para a pesquisa em educação (Bolívar, 2002; Ferrarotti, 2010).

O presente relato apresenta uma vivência que mostrou como as narrativas autobiográficas podem ser estratégias produtivas e significativas na formação inicial de futuros educadores, os quais revisitaram memórias sobre sua trajetória de vida, sua inserção nos grupos, sua subjetividade e singularidade, as quais permitiram a aprendizagem significativa de conceitos da área de Psicologia e da Sociologia da Educação.

A opção pelas narrativas autobiográficas foi baseada inicialmente em três premissas: a) primeiro, a consideração de que algo deveria ser feito para atuar frente ao desafio didático produzido pelo movimento crescente de ingresso de alunos no curso de Pedagogia com perfis diversificados, sobretudo percebido na am- plitude da faixa etária tendo ainda como pano de fundo de trajetórias de vida marcadas pela sinuosidade que repercutem em dificuldades de aprendizagem, manifestas na fragilidade das habilidades de relacionamento e adaptação, b) segundo, a necessidade de considerar outras possibilidades de ensino que pressupondo a afinidade entre áreas das ciências humanas (psicologia e sociologia da educação) partem da centralidade dos sujeitos e de suas experiencias como catalizadores de aprendizagens significativas, reflexivas e c) o entendimento de que a formação docente é um processo permanente e contínuo

Nesse sentido, a escolha pelas narrativas como opção metodológica pareceu ser a mais conveniente e oportuna à articulação entre teoria e prática, bem como a pesquisa e a formação para a docência promovendo a reflexão sobre si mesmo, seu lugar no mundo, seu passado e presente, bem como a análise da subjetividade que marca as situações relatadas o que derivou em maior clareza para projeção do futuro. O intuito era usar as narrativas autobiográficas como um instrumento de reflexão e ressignificação das experiências individuais de cada aluno nas disciplinas de Psicologia da Educação e Sociologia da Educação em um curso de Pedagogia. Partiu-se da hipótese de que, a escrita autobiográfica analisada, tendo como viés as teorias estudadas nas disciplinas de Psicologia e Sociologia da educação, traria uma compreensão mais reflexiva e significativa dos conceitos estudados nas disciplinas por parte dos alunos do curso de Pedagogia.

\section{Participantes}

Participaram da proposta trinta (30) e quarenta e cinco (45) alunos do primeiro período, matriculados no Curso de Pedagogia de uma Universidade pública, com faixa etária entre 18 e 48 anos de idade, de nível socioeconômico baixo e médio, respectivamente nos anos de 2014 e 2015. No momento da apresentação da Proposta foi feito um contrato de sigilo junto aos participantes, em que foi assegurado o caráter confidencial dos relatos. A proposta foi explicada durante as aulas e a escrita realizada em casa, a devolutiva individual das professoras foi realizada no diário de cada aluno, no qual foram feitas observações e pontuações a respeito da história de vida de cada um e as relações com as teorias estudadas nas duas disciplinas. Vale ressaltar que as duas turmas possuíam predominantemente alunos do gênero feminino.

\section{METODOLOGIA}

A metodologia utilizada nas disciplinas de Psicologia e Sociologia da Educação foi desenvolvida com base na produção da escrita biográfica realizada em um caderno 
do tipo diário para Psicologia e em forma de redações avulsas na de sociologia no transcorrer de um semestre nas duas turmas formadas em maioria pelo mesmo grupo. A fala, suas expansões e censuras foram respeitadas. Na disciplina de Psicologia e Sociologia da Educação, a metodologia se alicerçou na produção de três e quatro redações respectivamente. Organizou-se esse processo em três etapas inspiradas em Passeggi (2008):

1- Pré-texto. Caracterizada como uma escrita inicial cujo sentido é o de colocar alunos na condição de autores no processo de escrita.

2- Ação de escrita. Nessa etapa surgem os relatos e o auto-discurso. Há a emergência de fatos que constituem a história e a memória do sujeito. Os alunos relatavam primeiramente sua história de vida, passado e presente tanto para a disciplina de Psicologia quanto para a disciplina de Sociologia. Nessa fase cada professor solicitava relatos adaptados ao conteúdo de cada disciplina. Essa diretriz acionava fortemente uma espécie de filtro, um ajuste de lentes para trazer experiências com sentido.

3- Distanciar-se do objeto. Nessa etapa busca-se o reconhecimento do aluno de seu papel como interlocutor ativo do processo de escrita. É momento de colocar-se em análise, de ler-se heuristicamente.

$\mathrm{Na}$ disciplina de Psicologia da Educação, o aluno deveria relatar suas experiências em perguntas estruturadas pela professora da disciplina relacionadas às duas abordagens teóricas estudadas no semestre, contempladas pela ementa da Disciplina Psicologia da Educação I, a saber: a Teoria Comportamentalista e o Humanismo de Carl Rogers. Primeiramente, no diário solicitou-se aos alunos que descrevessem sua história de vida, fazendo um relato desde seu nascimento até a idade adulta atual, englobando infância, adolescência, entrada na vida adulta, assinalando os fatos mais marcantes dessas fases de desenvolvimento. Na segunda etapa, na parte relacionada à Teoria Comportamentalista solicitou-se o relato de situações vivenciadas pelo aluno em sua trajetória escolar e/ou de vida que lembrassem ou se remetessem a alguns conceitos como reforço positivo, reforço negativo, extinção, punição e generalização segundo Skinner. Na terceira etapa, a questão da Liberdade, Autonomia e Responsabilidade das escolas Humanistas foram discutidas dentro do contexto da teoria Rogeriana com perguntas iniciais como "Qual a escola dos seus sonhos", solicitando o resgate de vivências de práticas de ensino com professores humanistas e a sua visão emancipatória e transformadora da sociedade e da educação. Na disciplina de Psicologia foram solicitadas três escritas individuais no diário.

Nas aulas de Sociologia da Educação I cuja ementa orienta o estudo dos clássicos Emile Durkheim, Karl Marx e Max Weber, a fim de não influenciar essas pro- duções escritas, antes das aulas sobre o pensamento e os conceitos de Durkheim, Marx e Weber solicitou-se às alunas uma primeira escrita por meio da qual relatassem suas origens, os lugares, as pessoas, os costumes; enfim, sua "genealogia" e a infância. Depois, ao mesmo tempo em que as aulas iam transcorrendo foi solicitado que escrevessem sobre o ingresso na escola e a escolarização nas series iniciais. Pelo mesmo expediente foi solicitada uma terceira produção escrita, cujo tema era a escolha pela licenciatura e os planos futuros. Ao final dessa sequência houve um direcionamento no sentido de lerem as próprias produções e produzirem interpretações ou sentidos "sociológicos" sobre episódios importantes nelas destacados ou sobre os momentos "charneira" (Josso, 2010).

\section{RESULTADOS}

Na análise dos relatos solicitados no Diário da disciplina de Psicologia da Educação, relacionadas às situações envolvendo concepções de aprendizagem e desenvolvimento segundo as Teorias Behaviorista e Humanista percebeu-se uma modalidade de narração, na maioria dos casos, mais descritiva das situações vivenciadas e pouco avaliativa dos fenômenos, como dificuldades, frustrações, alegrias, violência, descritos no sentido de atribuir um valor ou julgamento a tais vivências. Os relatos envolvendo as vivências escolares e não escolares trouxeram a recordação e lembranças de inúmeras punições (e reforços negativos), exclusões e escassez de reforços positivos. Na abordagem humanista, a maioria dos alunos se identificou com a quebra de paradigmas proposta por Rogers e se sentiu seduzido pelos princípios humanistas de respeito, autonomia, liberdade e responsabilidade ausentes na maioria das vivências escolares dos participantes. As atividades artísticas também foram bastante destacadas pelas alunas como um aspecto a ser contemplado na escola dos seus sonhos. Um fato que saltou aos olhos foram as inúmeras narrativas de abuso sexual vivenciadas pelas alunas. Na disciplina de Psicologia, a narrativa autobiográfica auxiliou os alunos a aprender de maneira mais eficiente os conceitos propostos pelas duas abordagens teóricas. Mais especificamente no presente estudo, os dados apontaram que os conceitos de aprendizagem e desenvolvimento e os fatores que os influenciam sofreram modificações em decorrência do estudo das teorias Psicológicas, bem como da utilização das narrativas autobiográficas.

Já a análise das redações solicitadas na disciplina de Sociologia da Educação se orientou pela procura da aproximação entre o objeto produzido história-vida e as contribuições da tríade principal da Sociologia: sobre Durkheim, fato social, coerção, grupo social, punição, 
tipos de solidariedade entre outros conceitos; Marx, especialmente os conceitos de mais-valia, exploração, trabalho e alienação e Weber, burocracia, liderança, ação social, para a compreensão da sociedade. Uma primeira colocação a ser feita sobre as escritas é que elas mostraram que a Sociologia entendida como o estudo da sociedade preexiste sem a academia, já que todas as alunas pensam a sociedade de alguma forma. O que ocorre é que suas histórias escritas e lidas acionaram a produção de sentidos e interpretações que redirecionam ou consolidam tomadas de decisão, recusas e concordâncias. Vale ressaltar que houve uma evolução na qual se observa um afastamento em relação às descrições das emoções deflagradas pela memória e uma aproximação com o movimento de análise, significação de episódios, reestruturação cognitiva e socioemocional. Isso foi notado quando deparamos com uma redação inicial com acúmulo de adjetivação em expressões como "era bom", "era sofrido" e pela maniqueização dos episódios e depois isso vai sendo substituído, de sorte que observamos o aumento do expediente do auto-questionamento ou da tentativa de elaborar outras explicações e sentidos. Destaca-se que com maior recorrência foram percebidos nessa fase: a) a leitura funcionalista de mundo e sociedade associada ao pensamento de Durkheim que englobava o lugar ou não lugar da mulher, do camponês, do trabalhador, b) aspectos da alienação e da exploração pelo capital compreendidos como a falta de esclarecimento e como produto da exploração social associados ao pensamento de Marx, c) os tipos de ação social e de lideranças associados a Weber. Portanto, assim como na Psicologia, na disciplina de Sociologia o sentido processual foi no descritivo-avaliativo. Uma escrita síntese em especial, que foi obtida na Sociologia, mostrou o potencial do processo de uma aluna aqui denominada de Ester que escreveu na produção final sobre as interpretações de si: "Agora sei que a culpa não foi sempre minha. A explicação é ter nascido negra, pobre e mulher em um país de lugares marcados".

Ao fazer-se uma análise geral da escrita de si das alunas, percebem-se avanços e retrocessos nos conceitos trabalhados nas duas disciplinas, assim como reinterpretações das experiências relatadas em decorrência do uso das narrativas autobiográficas e do estudo das Teorias Psicológicas e Sociológicas. Fato comum ocorrido nas duas disciplinas foi a dificuldade da turma em escrever a respeito de si mesma a partir de uma perspectiva reflexiva; o tomar contato com sua própria história de vida, por vezes é doloroso. Outra dificuldade se remete à necessidade de refletir sobre os fatos narrados, embasando nas teorias estudadas, sendo necessário nesse processo.

\section{CONSIDERAÇÕES FINAIS}

Tendo por base o relato dos alunos que a escrita da sua história de vida articulada a determinado arcabouço teórico da Psicologia e Sociologia da Educação traria uma compreensão mais reflexiva, promovendo uma aprendizagem mais significativa, verificou-se que, assim como apontado pela literatura (Galvão, 2005; Josso, 2010; Passegi, 2011) que essa vivência apoiou a aprendizagem desses alunos como futuros profissionais da área da Educação.

Segundo Nóvoa (2002, p. 9) "não há aprendizagem sem experiência e sem uma reflexão pessoal, auto biográfica sobre a experiência. O que verdadeiramente importa não é a realidade vivida, mas a realidade sentida, pensada interpretada". Infelizmente, algumas investigações atestam que a formação inicial tem trazido poucas contribuições para o exercício da docência (Josso, 2010). A superação da dicotomia sentida pelos alunos entre teoria e prática na formação inicial de futuros educadores é apontada como um dos grandes desafios vivenciados pelo docente no ensino superior. A narrativa autobiográfica pode ser um dos possíveis caminhos para superar a fragmentação entre teoria e prática promovendo uma aprendizagem realmente significativa por parte do futuro docente. A literatura aponta que a solicitação de relembrar sua própria história de vida, refletir, selecionar fatos e narrar tendo como base uma abordagem teórica exige um esforço cognitivo e metacognitivo que faz com que haja um processo pessoal de auto formação, auto reflexão de conteúdos da formação inicial que auxiliarão a prática do futuro docente (Passegi, 2011).

À guisa de conclusão, enquanto educadoras atuando na formação de professores para a educação infantil, percebe-se a existência de vários desafios para a realização de um trabalho com a subjetividade e interdisciplinaridade: a dificuldade de analisar de forma crítica e analítica sua história de vida; a dificuldade em fazer uma aproximação entre os processos subjetivos individuais e os formativos. As observações quanto à possibilidade da utilização das Narrativas autobiográficas na área da Psicologia e Sociologia da Educação em sua interface com a Educação são relevantes não apenas pela prática pedagógica, mas também por se constituir num campo fecundo de intervenção e pesquisa podendo portanto ser de grande auxílio para o professor como ferramenta nas discussões na formação inicial de futuros professores.

\section{REFERÊNCIAS}

Bolívar, A. (2002). “¿De nobis ipsis silemus?”: Epistemología de la investigación biográfico-narrativa en educación. Revista Electrónica de Investigación Educativa, 4(1). Recuperado 
de http://redie.uabc.uabc.mx/vol4no1/contenido-bolivar. html.

Coulon, A. (1995). Etnometodologia. Petrópolis, RJ: Vozes

Ferrarotti, F. (2010). Sobre a autonomia do método biográfico. In Nóvoa, A.; Finger, M. (Eds.). O método (auto) biográfico e a formação (pp. 31-57). Natal, RN: EDUFRN; São Paulo: Paulus.

Galvão, C. (2005). Narrativas em Educação. Ciência \& Educação, 11(2), 327-345. https://dx.doi.org/10.1590/ S1516-73132005000200013

Josso, M. (2010). Experiência de vida e formação. Natal: RN: Edufrn.

Larrosa, J. (2011). Experiência e alteridade em educação. Reflexão \& Ação, 19(2), 4-27

Nóvoa, A. (1992). Os professores e a sua formação. Lisboa,
Dom Quixote.

Nóvoa, A. (2002). Formação de professores e trabalho pedagógico. Lisboa: Educa.

Passegi, M. C. (2008). Memoriais: injunção institucional e sedução autobiográfica. In Passegi, M. C.; Souza, C. (Eds.), (Auto)biografia: formação, territórios e saberes (pp. 103132). São Paulo: Paulus; Natal: EDUFRN.

Passeggi, M. C. (2011). Narrativa autobiográfica: uma prática reflexiva na formação docente. Educação, 34(2), 147-156.

Ricoeur, P. (2007). A memória, a história, o esquecimento (François, A., Trad.). Campinas, SP: Editora da UNICAMP.

Souza, E. C.; Sousa, C. P.; Catani, D. B. (2007). La reserche (auto) biographique et l'invention de soi au Bresil. [Resumo]. In Colloque International Le Biographique, la réflexivité et les temporalités. Articuler Langues, cultures et formation (pp.25-27). Tours-França: Université François Rabelais.

Recebido: 15 de maio de 2019 Aprovado: 25 de setembro de 2019 